\title{
Toll-like receptor 4 is expressed and functional in late endothelial progenitor cells
}

\author{
MIN YU ${ }^{1,2^{*}}$, CANTIAN WANG ${ }^{1 *}$, GUONING ZENG $^{1}$, LIHONG ZHOU $^{1}$, \\ TINGTING CHEN $^{1}$, XUERUI TAN ${ }^{1}$ and YANPING WANG ${ }^{1}$ \\ ${ }^{1}$ Department of Cardiology; ${ }^{2}$ Molecular Biology Laboratory, The First Affiliated Hospital, \\ Shantou University Medical College, Shantou, Guangdong 515041, P.R. China
}

Received November 17, 2016; Accepted July 7, 2017

DOI: 10.3892/mmr.2017.7291

\begin{abstract}
It has been previously demonstrated that lipopolysaccharides (LPS) inhibit the viability, migration, adhesion and in vitro angiogenesis of late endothelial progenitor cells (EPCs). However, the mechanisms underlying this LPS-induced impairment of late EPC functional activity are unknown. The aim of the present study was to investigate whether Toll-like receptor 4 (TLR4) is expressed and functional on late EPCs, using late EPCs of 3-5 passages. Cells were deprived of serum for $24 \mathrm{~h}$ prior to experiments and incubated with $10 \mu \mathrm{g} / \mathrm{ml}$ LPS for $24 \mathrm{~h}$ with or without pretreatment with $2 \mu \mathrm{g} / \mathrm{ml}$ TLR4 signaling inhibitor CLI-095 for $30 \mathrm{~min}$. The viability, migration, adhesion and in vitro angiogenesis, as well as the expression of silent information regulator 1 (SIRT1), in late EPCs were evaluated. Treatment with $10 \mu \mathrm{g} / \mathrm{ml}$ LPS decreased the viability, migration and adhesion abilities, and in vitro angiogenesis of late EPCs. Pretreatment with the TLR4 signaling inhibitor reversed this LPS-induced dysfunction of late EPCs. LPS downregulated the expression of SIRT1 protein, however, blocking TLR4 attenuated the effect of LPS on SIRT1 expression. Therefore, the results of the present study indicate that LPS impaired the functional activity of late EPCs via TLR4, which may be associated with decreased SIRT1 expression.
\end{abstract}

\section{Introduction}

In 1997, Asahara et al (1) isolated endothelial progenitor cells (EPCs) from adult peripheral blood and revealed that EPCs

Correspondence to: Mrs. Yanping Wang, Department of Cardiology, The First Affiliated Hospital, Shantou University Medical College, 57 Changping Road, Shantou, Guangdong 515041, P.R. China

E-mail: stmedwang@126.com

*Contributed equally

Key words: lipopolysaccharide, late endothelial progenitor cells, Toll-like receptor 4, Silent information regulator 1, lung injury, functional activity served an important role in the angiogenesis of ischemic tissues. Following this discovery, EPCs have been investigated. EPCs have since been observed in umbilical cord blood, bone marrow and tissue resident niches (2-4). In addition, the associations between EPCs, and cardiovascular risk factors and the outcome of cardiovascular diseases have been investigated in depth. Associations between EPCs and lung diseases have also been reported (5-7). Previous studies have demonstrated that transplantation of circulating EPCs attenuated lung injury and improved survival in rats with lung injury (8-10). These results suggested that EPCs may serve an important role in lung injury repair.

An increasing body of evidence has revealed that EPCs can be divided into two populations: Early and late EPCs $(11,12)$. Early EPCs have a spindle-like shape and appear in culture following 3-5 days, gradually disappearing in 4 weeks. They also have a low proliferative capacity and promote angiogenesis via the secretion of cytokines. By contrast, late EPCs, which have a cobblestone shape, appear following 1-4 weeks following plating and exhibit a high proliferative activity, providing a number of endothelial cells that contribute to the repair of damaged endothelium and enhance angiogenesis.

Unlike early EPCs, late EPCs have not been studied in great detail. The authors previously demonstrated that lipopolysaccharide (LPS) inhibited the viability, migration, adhesion and in vitro angiogenesis of late EPCs (13). However, the mechanisms by which LPS induces the impairment of late EPC functional activity remain unknown. A previous study revealed that LPS can exert proinflammatory effects via the toll-like receptor 4 (TLR4) signaling pathway and also decreased the expression of silent information regulator 1 (SIRT1), which in turn exerts anti-inflammatory effects against cellular injury (14). It is currently unclear whether the TLR4 signaling pathway is involved in the LPS-induced impairment of late EPC functional activity thus, the aim of the present study was to investigate whether TLR4 is expressed and functional on late EPCs.

\section{Materials and methods}

Isolation, culture and characterization of late EPCs. The present study was approved by the ethics committee of Shantou University Medical College (Guangdong, China). Late EPCs were isolated and cultured according to previously 
described techniques $(3,13,15-17)$. Mononuclear cells (MNCs) were isolated from previously obtained umbilical cord blood from the First Affiliated Hospital of Shantou University Medical College (13) by Ficoll density gradient centrifugation (TDL-5-A, Shanghai Anting Scientific Instrument Factory, Shanghai, China) at $1,000 \mathrm{x}$ g for $20 \mathrm{~min}$ at room temperature and cultured on 6-well plates with endothelial cell growth medium (EGM)-2 (Lonza Group, Ltd., Basel, Switzerland). Following culturing for $24 \mathrm{~h}$ at $37^{\circ} \mathrm{C}$, non-adherent cells were washed with EGM-2 and attached cells were cultured with EGM-2, changed daily for the first week and then every other day until passage. Late EPCs were double positive both for 1,1-dioctadecyl-3,3,3,3-tetramethylindocarbocyanine-labeled acetylated low-density lipoprotein (DiI-acLDL; Invitrogen; Thermo Fisher Scientific, Inc., Waltham, MA, USA) uptake and fluorescein-isothiocyanate (FITC)-conjugated Ulex europaeus agglutinin lectin (UEA-1; Sigma-Aldrich; Merck KGaA, Darmstadt, Germany) binding. Cells were further characterized by demonstrating that they expressed endothelial cell markers including von Willbrand factor, kinase insert domain receptor, CD105, CD146 and CD144, however, they did not express hematopoietic cell-specific surface antigens including CD11b, CD14 and CD45, which had been verified in our previous study (13).

Expression of TLR4 on late EPCs. The expression of TLR4 was detected by immunostaining, western blotting and reverse transcription-polymerase chain reaction (RT-PCR).

Immunocytochemistry. To detect the expression of TLR4, late EPCs were fixed in 2\% paraformaldehyde for $10 \mathrm{~min}$ at room temperature and then washed three times with PBS for 5 min each. Following blocking with $10 \%$ goat serum (Wuhan Boster Biological Technology, Ltd., Wuhan, China) for $30 \mathrm{~min}$ at room temperature, cells were incubated with primary polyclonal rabbit anti-TLR4 (cat. no. 19811-1-AP; 1:100; ProteinTech Group, Inc., Chicago, IL, USA) at $4^{\circ} \mathrm{C}$ overnight, and then incubated with polyclonal anti-rabbit FITC-conjugated secondary antibodies (cat. no. sc-2012; 1:100; Santa Cruz Biotechnology, Inc., Dallas, TX, USA) at room temperature for $2 \mathrm{~h}$. Fluorescent images were obtained using an inverted microscope.

Western blot analysis. The expression of the TLR4 protein was also investigated. Cells were cultured in a $60 \mathrm{~mm}$ dish and lysed using a cell lysis buffer (cat. no. P0013; Beyotime Institute of Biotechnology, Haimen, PR China). Protein concentration was determined by BCA assay. Proteins (15 $\mu \mathrm{g} / \mathrm{lane})$ were denatured, separated by SDS-PAGE on a $10 \%$ gel and electrotransferred to a polyvinylidene difluoride (PVDF) membrane. Membranes were blocked for $1 \mathrm{~h}$ at room temperature with $5 \%$ non-fat milk in TBS containing $0.05 \%$ Tween-20 (TBST) and incubated with the polyclonal rabbit anti-TLR4 antibody (1:500) at $4^{\circ} \mathrm{C}$ overnight, followed by $1 \mathrm{~h}$ incubation at room temperature with a horseradish peroxidase-conjugated secondary goat polyclonal anti-rabbit antibody (cat. no. A0545; 1:1,000; Sigma-Aldrich; Merck KGaA, Darmstadt, Germany). The protein bands were visualized using SuperSignal West Pico Chemiluminescent Substrate (cat. no. 34079; Thermo Fisher Scientific, Inc.).
$R T-P C R$. To investigate the expression of TLR4 mRNA, total RNA was extracted from late EPCs using TRIzol according to the method described by the manufacturer (Thermo Fisher Scientific, Inc.). Total RNA (200 ng) was reverse transcribed and amplified with RNA PCR kit (cat. no. DRR019A; Takara Bio, Inc., Otsu, Japan) using following primers: TLR-4, forward 5'-GTTCTCTACTCTTGTGCTTGT-3' and reverse, 5'-TGT TAATCTCTTACTGTGCCTAAT-3'. The thermocycling conditions were as follows: Denaturation at $96^{\circ} \mathrm{C}$ for $5 \mathrm{~min}$; followed by 30 cycles of $96^{\circ} \mathrm{C}$ for $45 \mathrm{sec}, 57^{\circ} \mathrm{C}$ for $30 \mathrm{sec}$ and $72^{\circ} \mathrm{C}$ for $30 \mathrm{sec}$; and then 1 cycle at $72^{\circ} \mathrm{C}$ for $10 \mathrm{~min}$. The amplification products were electrophoresed on $1 \%$ agarose gel in Tris base-boric acid-EDTA buffer solution containing the GoldView ${ }^{\mathrm{TM}}$ nucleic acid stain and visualized using UV transilluminator apparatus.

Cell treatments. Late EPCs from passages 3-5 were used for subsequent experiments and were divided into the following groups: Control, CLI-095 only treatment, LPS only treatment and LPS+CLI-095 treatment. Cells were deprived of serum for $24 \mathrm{~h}$ at $37^{\circ} \mathrm{C}$ prior to experiments, then cells in the treatment groups were pretreated with or without $2 \mu \mathrm{g} / \mathrm{ml}$ of the TLR4 signaling inhibitor CLI-095 (Invitrogen; Thermo Fisher Scientific, Inc.) for $30 \mathrm{~min}$ and then further incubated with or without $10 \mu \mathrm{g} / \mathrm{ml}$ LPS (Sigma-Aldrich; Merck KGaA) for $24 \mathrm{~h}$ at $37^{\circ} \mathrm{C}$.

Effects of CLI-095 on functional activity of late EPCs. The functional activity of late EPCs were determined according to previously described methods (13,15-17).

MTT assay. The effect of CLI-095 on the viability of late EPCs was evaluated with an MTT assay. Late EPCs $\left(1 \times 10^{4}\right)$ were digested, cultured in 96-well culture plates (150 $\mu \mathrm{l} /$ well), and then treated with either LPS $(10 \mu \mathrm{g} / \mathrm{ml})$ or CLI-095 $(2 \mu \mathrm{g} / \mathrm{ml})$. Following culture for $24 \mathrm{~h}$, late EPCs were supplemented with $100 \mu$ l EGM-2 containing MTT ( 0.5 g/l; Sigma-Aldrich; Merck $\mathrm{KGaA}$ ) and incubated for a further $4 \mathrm{~h}$ at $37^{\circ} \mathrm{C}$. Then, the supernatant was aspirated and $150 \mu \mathrm{l}$ dimethyl sulfoxide was added. The late EPC preparation was shaken for $10 \mathrm{~min}$, prior to analysis of the optical density value measured at $490 \mathrm{~nm}$.

Boyden chamber assay. The migration activity of late EPCs was assessed via a Boyden chamber assay. EGM-2 (100 $\mu \mathrm{l})$ containing $2 \times 10^{4}$ EPCs was added to the upper chamber of a transwell cell culture insert ( $8 \mu \mathrm{m}$ pore size; BD Biosciences, Franklin Lakes, NJ, USA). EGM-2 (0.5 ml) containing $10 \%$ fetal bovine serum (Gibco; Thermo Fisher Scientific, Inc.) was placed in the lower chamber. Following incubation for $24 \mathrm{~h}$ at $37^{\circ} \mathrm{C}$, the upper side of the membrane was wiped gently with a cotton ball. Then, the membranes were washed with PBS and fixed with $100 \%$ methanol for $20 \mathrm{~min}$ at room temperature. For quantification, cells were stained with 4',6-diamidino-2-phenylindole solution for $20 \mathrm{~min}$ at room temperature. Cells migrating into the lower chamber were counted by eye using light microscopy in 5 random high-power (magnification, x100) microscopic fields, and the average numbers of cells/field were determined.

Cell adhesion assay. The adhesive capacity was determined using a cell adhesion assay. Late EPCs $\left(5 \times 10^{3}\right)$ in $50 \mu 1$ EGM-2 were replated onto a 96-well plate and incubated for $30 \mathrm{~min}$ at 
$37^{\circ} \mathrm{C}$. The non-adherent cells were removed and the number of adherent cells was counted by eye using light microscopy.

Capillary formation. In vitro vasculogenesis capacity was evaluated by analyzing the capillary formation in Matrigel (BD Biosciences). Late EPCs (1x10 $)$ suspended in $100 \mu 1$ EGM-2 were plated onto a 96-well plate preincubated with Matrigel diluted with EGM-2 (1:1). Following incubation for 3-9 h at $37^{\circ} \mathrm{C}$, tube formation was observed under a light microscope (one field in one well of 96-well plate under light microscopy at 40x magnification) and the length of the capillary tubes in a random field of each well was recorded.

Effects of CLI-095 on the expression of SIRT1 on late EPCs. The expression of the SIRT1 protein was analyzed following the methods described in the aforementioned western blotting section. Proteins ( $15 \mu \mathrm{g} /$ lane) were separated by SDS-PAGE on $10 \%$ gels and transferred to a PVDF membrane, which again was blocked with 5\% non-fat milk and TBST. Membranes were incubated with a polyclonal rabbit anti-SIRT1 antibody (cat. no. sc-15404; 1:1,000; Santa Cruz Biotechnology, Inc.) overnight at $4{ }^{\circ} \mathrm{C}$, followed by a $1 \mathrm{~h}$ incubation at room temperature with a secondary goat polyclonal anti-rabbit antibody (cat. no. A0545; 1:1,000; Sigma-Aldrich; Merck KGaA). $\beta$-actin (anti- $\beta$-actin antibody, cat. no. sc-130656; 1:1,000; Santa Cruz Biotechnology, Inc.) was used as an internal control. The protein bands were visualized with an ECL kit (Thermo Fisher Scientific, Inc.) and images were analyzed by Quantity One version 4.62 (Bio-Rad Laboratories, Inc., Hercules, CA, USA).

Statistical analysis. All data are presented as the mean \pm standard deviation. Differences between group were assessed by one-way analysis of variance, followed by Tukey's multiple comparison tests using SPSS version 16.0 software (SPSS, Inc., Chicago, IL, USA). $\mathrm{P}<0.05$ was considered to indicate a statistically significant difference.

\section{Results}

TLR4 is expressed on late EPCs. To investigate the expression of TLR4, late EPCs were incubated with TLR4 antibodies. As demonstrated in Fig. 1A, immunostaining demonstrated that late EPCs expressed TLR4. In addition, the expression of TLR4 protein and mRNA was further verified by western blotting (Fig. 1B) and RT-PCR (Fig. 1C), respectively.

Effect of CLI-095 on late EPC viability. The effect of CLI-095 on late EPC viability was evaluated using an MTT assay (Fig. 2). Treatment with $10 \mu \mathrm{g} / \mathrm{ml}$ LPS significantly decreased late EPC viability. To investigate the role of TLR4 in late EPC viability, the effect of the TLR4 signaling inhibitor CLI-095 $(2 \mu \mathrm{g} / \mathrm{ml})$ on late EPC viability was investigated. Pretreatment with CLI-095 alone for $30 \mathrm{~min}$ did not affect viability when compared with the control. However, when compared with LPS only treatment, pretreatment with CLI-095 was able to reverse the decrease in viability induced by LPS (Fig. 2).

Effect of CLI-095 on late EPC migration. The effect of CLI-095 on late EPCs migration was analyzed using a modified Boyden chamber assay. When compared with the control group, the
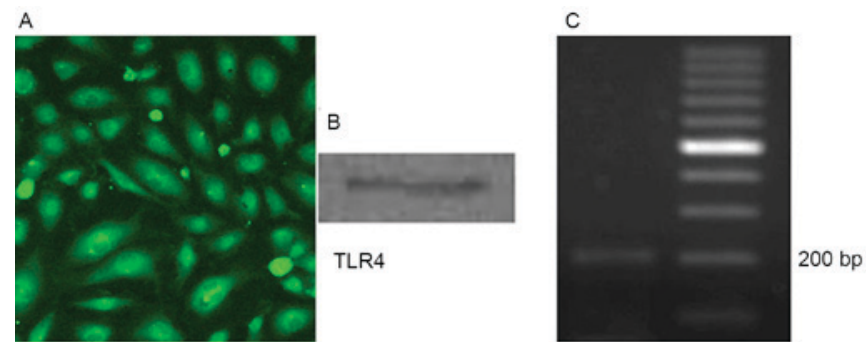

Figure 1. Expression of TLR4 on late EPCs was detected by (A) immunocytochemistry (magnification, x100), (B) western blotting and (C) RT-PCR. Staining revealed that TLR4 is expressed on late EPCs, which was also verified by western blotting and RT-PCR. TLR4, toll-like receptor 4; EPCs, endothelial progenitor cells; RT-PCR, reverse transcription-polymerase chain reaction.

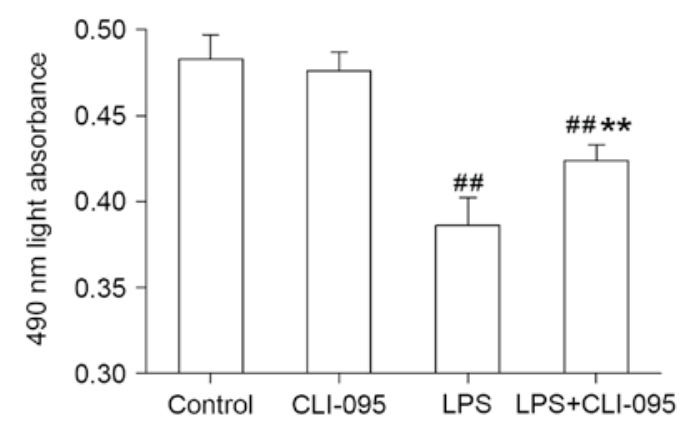

Figure 2. Effect of TLR4 signaling inhibition on late EPC viability. LPS treatment $(10 \mu \mathrm{g} / \mathrm{ml})$ decreased late EPC viability. Pretreatment with $2 \mu \mathrm{g} / \mathrm{ml}$ TLR4 signaling inhibitor CLI-095 attenuated the LPS-induced decrease in late EPCs viability. Data are presented as the mean \pm standard deviation $(\mathrm{n}=5) .{ }^{\# \#} \mathrm{P}<0.01$ vs. control; ${ }^{* *} \mathrm{P}<0.01$ vs. LPS group. TLR4, toll-like receptor 4; EPCs, endothelial progenitor cells; LPS, lipopolysaccharides.

migratory activity of late EPCs incubated with $10 \mu \mathrm{g} / \mathrm{ml}$ LPS was significantly decreased (Fig. 3). Pretreatment with $2 \mu \mathrm{g} / \mathrm{ml}$ CLI-095 only for $30 \mathrm{~min}$ did not affect migration; however, when combined with treatment with LPS it significantly inhibited the decrease in LPS-induced late EPC migration (Fig. 3).

Effect of CLI-095 on late EPC adhesiveness. The effect of CLI-095 on the adhesion of late EPCs was evaluated using an adhesion assay. Treatment with $10 \mu \mathrm{g} / \mathrm{ml}$ LPS only significantly impaired adhesion, however, combined treatment with $2 \mu \mathrm{g} / \mathrm{ml}$ CLI-095 attenuated this effect (Fig. 4). CLI-095 pretreatment alone did not significantly alter adhesion (Fig. 4).

Effect of the TLR4 inhibitor CLI-095 on late EPC vasculogenesis. An in vitro cell adhesion assay was used to evaluate the effect of CLI-095 on late EPC vasculogenesis. Following plating of late EPCs on to a basement membrane matrix, tube formation was observed. Incubation with $10 \mu \mathrm{g} / \mathrm{ml} \mathrm{LPS}$ only significantly decreased tube length; however, CLI-095 pretreatment $(2 \mu \mathrm{g} / \mathrm{ml})$ alone did not significantly alter tube length (Fig. 5). Combined treatment with LPS and CLI-095 increased the tube length when compared to LPS treatment only, thereby attenuating the LPS-induced effects (Fig. 5).

Effect of the TLR4 inhibitor CLI-095 on the expression of SIRT1. To investigate the potential mechanisms underlying the 


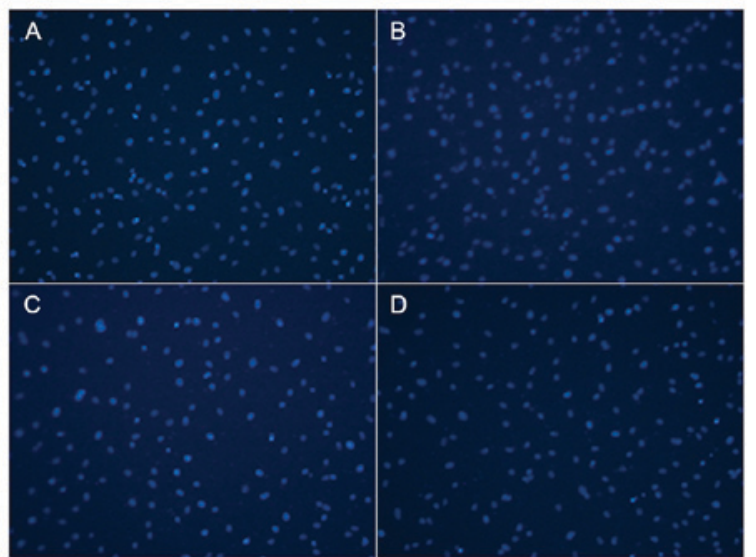

$E$

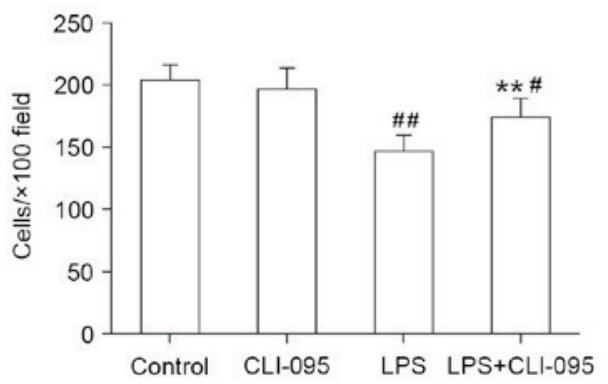

Figure 3. Effect of TLR4 signaling inhibition on late EPCs migration in the (A) control, (B) CLI-095 only, (C) LPS only and (D) LPS+CLI-095 treatment groups (magnification, x100). (E) Following the plating of late EPCs in the upper chamber of a transwell cell culture insert, the cells migrated into the lower chamber. Pretreatment with $2 \mu \mathrm{g} / \mathrm{ml}$ TLR4 signaling inhibitor CLI-095 alone for $30 \mathrm{~min}$ had no effect on late EPC migration. Treatment with $10 \mu \mathrm{g} / \mathrm{ml}$ LPS decreased late EPC migration. However, the effect of LPS on late EPC migration was attenuated when used in combination with $2 \mu \mathrm{g} / \mathrm{ml} \mathrm{CLI}-095$. Data are presented as the mean \pm standard deviation $(\mathrm{n}=5) .{ }^{*} \mathrm{P}<0.05,{ }^{\# \#} \mathrm{P}<0.01$ vs. control; ${ }^{* *} \mathrm{P}<0.01$ vs. LPS group. TLR4, toll-like receptor 4; EPCs, endothelial progenitor cells; LPS, lipopolysaccharides.

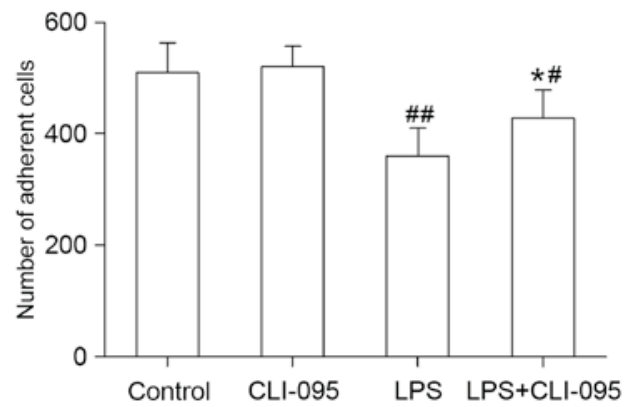

Figure 4. Effect of TLR4 signaling inhibition on late EPC adhesion. Treatment with $10 \mu \mathrm{g} / \mathrm{ml}$ LPS decreased late EPC adhesive activity. Pretreatment with $2 \mu \mathrm{g} / \mathrm{ml}$ TLR4 signaling inhibitor CLI-095 attenuated this LPS-induced decrease in late EPC adhesion. Data are presented as the mean \pm standard deviation $(\mathrm{n}=5) .{ }^{\#} \mathrm{P}<0.05,{ }^{\# \#} \mathrm{P}<0.01$ vs. control; ${ }^{*} \mathrm{P}<0.05$ vs. LPS group. TLR4, toll-like receptor 4; EPCs, endothelial progenitor cells; LPS, lipopolysaccharides.

effects of LPS treatment, the present study assessed the effect of LPS on SIRT1 expression in late EPCs. As demonstrated in Fig. 6, $10 \mu \mathrm{g} / \mathrm{ml}$ LPS significantly downregulated the expression of SIRT1 protein. Pretreatment with $2 \mu \mathrm{g} / \mathrm{ml}$ CLI-095 reversed this LPS-induced decrease in SIRT1 expression to an extent.

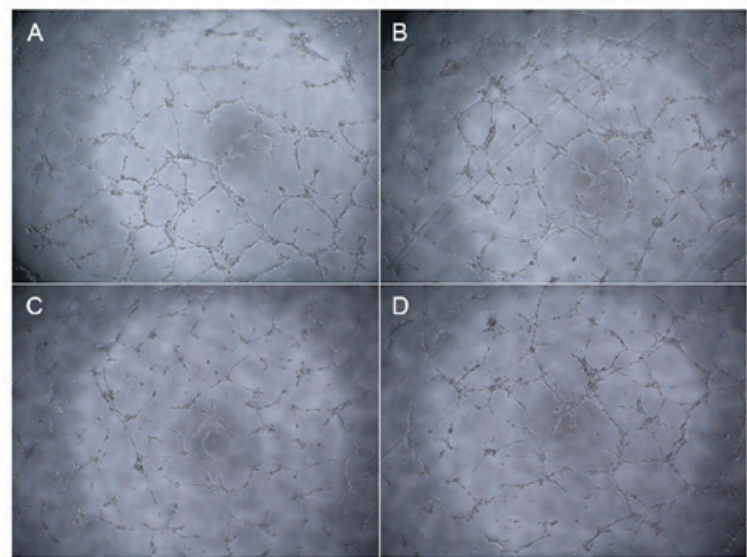

E

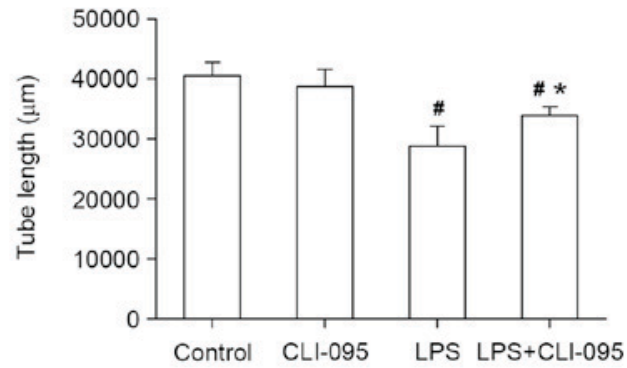

Figure 5. Effect of TLR4 signaling inhibition on the capacity of late EPC for vasculogenesis (magnification, $x 40$ ). Seeding of late EPCs on Matrigel resulted in the formation of a capillary network in the (A) control, (B) CLI-095 only, (C) LPS only and (D) LPS+CLI-095 treatment groups. (E) Pretreatment with $2 \mu \mathrm{g} / \mathrm{ml}$ CLI-095 alone for 30 min exhibited no effect on late EPC vasculogenesis; however, $10 \mu \mathrm{g} / \mathrm{ml}$ LPS decreased late EPC vasculogenesis. This LPS-induced effect on late EPC vasculogenesis was attenuated by CLI-095. Data are presented as the mean \pm standard deviation $(\mathrm{n}=5)$. ${ }^{\text {}} \mathrm{P}<0.05$ vs. control; ${ }^{*} \mathrm{P}<0.05$ vs. LPS group. TLR4, toll-like receptor 4 ; EPCs, endothelial progenitor cells; LPS, lipopolysaccharides.

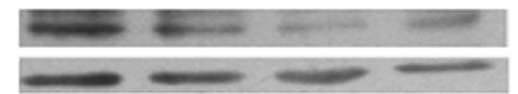
SIRT1 $\beta$-actin

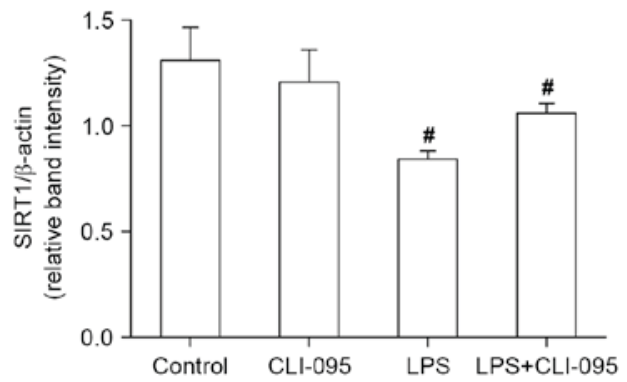

Figure 6. LPS downregulated the expression of SIRT1 in late EPCs. Treatment with $10 \mu \mathrm{g} / \mathrm{ml}$ LPS decreased SIRT1 expression; however, this was attenuated by inhibiting TLR4 with $2 \mu \mathrm{g} / \mathrm{ml}$ CLI-095. Data are presented as the mean \pm standard deviation $(n=3) .{ }^{~} \mathrm{P}<0.05$ vs. control. LPS, lipopolysaccharides; SIRT1, silent information regulator 1; EPCs, endothelial progenitor cells; TLR4, toll-like receptor 4.

\section{Discussion}

The results of the present study have demonstrated that TLR4 
is expressed on late EPCs. In addition, LPS downregulated the expression of SIRT1 via TLR4 and the TLR4 signaling inhibitor CLI-095 attenuated the LPS-induced dysfunction of late EPCs.

TLRs are evolutionarily-conserved protein receptors that serve an important role in the recognition of pathogen-associated molecular patterns. An increasing body of evidence has revealed that TLRs are associated with a number of pathophysiological processes, including cancer, and autoimmune, infectious and cardiovascular diseases $(18,19)$. Since TLRs were first described in 1997 (20), 11 TLRs and their respective ligands have subsequently been identified in humans, of which, TLR4 is by far the most intensively studied and the best functionally characterized. To date, it has been reported that TLR4 is expressed on various cell types including hepatocytes and, epithelial, endothelial and smooth muscle cells. As a cellular receptor for endotoxin receptors, TLR4 serves a key role in the recognition of Gram-negative bacterial components (LPS) and in LPS-induced acute lung injury. However, a body of evidence has demonstrated that several other receptors and the TLR4-independent pathway may also be involved in the LPS-associated effects (21-24).

The authors previously demonstrated that LPS impaired the viability, migration, adhesion and in vitro vasculogenesis capacity of late EPCs (13). On this basis, the present study revealed that inhibition of TLR4 signaling can reverse this impairment of functional activity in late EPCs, which suggested that TLR4 signaling pathways may be involved in the LPS-induced dysfunction of late EPCs.

LPS activates two distinct intracellular signaling pathways via TLR4 (25): The myeloid differentiation primary response gene 88 -dependent and TIR-domain-containing adapter-inducing interferon- $\beta$-dependent signaling pathways. However, the mechanism underlying the action of LPS on late EPCs remains to be determined. SIRT1, the most well-studied protein of the sirtuin family, has been shown to mediate the pathogenesis of a variety of chronic diseases, including obesity (26), diabetes (27) and cardiovascular diseases (28). Recent studies have revealed that SIRT1 can exhibit pronounced anti-inflammatory properties $(29,30)$. It has been previously established that LPS decreased the expression of SIRT1 and increased the levels of TNF- $\alpha$ and interleukin-6 (14). In addition, TNF- $\alpha$ reduced SIRT1 expression in endothelial cells (31) and human chondrocytes (32); however, resveratrol (a known SIRT1 activator) suppressed this effect. The dysregulation of SIRT1 promoted the nicotinamide adenine dinucleotide phosphate oxidase-dependent production of reactive oxygen species and impaired endothelial function (33). By contrast, activation of SIRT1 by resveratrol increased vascular oxidative stress resistance (34) and protected endothelial cells (35) and cardiomyocytes (36) against oxidative stress. In the present study, LPS downregulated the expression of SIRT1, which was reversed by inhibiting TLR4 signaling. These results suggest that LPS may impair late EPCs, at least in part, by activating TLR4 and decreasing the expression of SIRT1. However, whether activation of SIRT1 by resveratrol can protect late EPCs against LPS-induced injury requires further investigation.

A few limitations were apparent in the present study. Recent studies have demonstrated that LPS can exert its effects though TLR4-dependent and -independent pathways $(22,37)$. However, only the TLR4-dependent pathway was investigated in the present study. Thus, whether the TLR4-independent pathway is also involved requires further elucidation. Although LPS decreased the expression of SIRT1 via TLR4, the mechanism underlying how TLR4 activation affected SIRT1 expression was not determined. The effects of LPS on late EPCs in vivo may be different from those observed in vitro.

In conclusion, the present study demonstrated that LPS impaired the functional activity of late EPCs via TLR4, which may be associated with a decrease in the expression of SIRT1.

\section{Acknowledgements}

The present study was supported in part by the Specialized Research Fund for the Doctoral Program of Higher Education of China (grant no. 20114404110006).

\section{References}

1. Asahara T, Murohara T, Sullivan A, Silver M, van der Zee R, Li T, Witzenbichler B, Schatteman G and Isner JM: Isolation of putative progenitor endothelial cells for angiogenesis. Science 275: 964-967, 1997.

2. Ingram DA, Mead LE, Tanaka H, Meade V, Fenoglio A, Mortell K, Pollok K, Ferkowicz MJ, Gilley D and Yoder MC: Identification of a novel hierarchy of endothelial progenitor cells using human peripheral and umbilical cord blood. Blood 104: 2752-2760, 2004

3. Lin Y, Weisdorf DJ, Solovey A and Hebbel RP: Origins of circulating endothelial cells and endothelial outgrowth from blood. J Clin Invest 105: 71-77, 2000.

4. Ingram DA, Mead LE, Moore DB, Woodard W, Fenoglio A and Yoder MC: Vessel wall-derived endothelial cells rapidly proliferate because they contain a complete hierarchy of endothelial progenitor cells. Blood 105: 2783-2786, 2005.

5. Palange $P$, Testa U, Huertas A, Calabrò L, Antonucci $R$ Petrucci E, Pelosi E, Pasquini L, Satta A, Morici G, et al: Circulating haemopoietic and endothelial progenitor cells are decreased in COPD. Eur Respir J 27: 529-541, 2006.

6. Burnham EL, Taylor WR, Quyyumi AA, Rojas M, Brigham KL and Moss M: Increased circulating endothelial progenitor cells are associated with survival in acute lung injury. Am J Respir Crit Care Med 172: 854-860, 2005

7. Yamada M, Kubo H, Ishizawa K, Kobayashi S, Shinkawa M and Sasaki H: Increased circulating endothelial progenitor cells in patients with bacterial pneumonia: Evidence that bone marrow derived cells contribute to lung repair. Thorax 60: 410-413, 2005.

8. Yamada M, Kubo H, Kobayashi S, Ishizawa K, Numasaki M, Ueda S, Suzuki T and Sasaki H: Bone marrow-derived progenitor cells are important for lung repair after lipopolysaccharide-induced lung injury. J Immunol 172: 1266-1272, 2004.

9. Lam CF, Liu YC, Hsu JK, Yeh PA, Su TY, Huang CC, Lin MW, Wu PC, Chang PJ and Tsai YC: Autologous transplantation of endothelial progenitor cells attenuates acute lung injury in rabbits. Anesthesiology 108: 392-401, 2008.

10. Mao M, Wang SN, Lv XJ, Wang Y and Xu JC: Intravenous delivery of bone marrow-derived endothelial progenitor cells improves survival and attenuates lipopolysaccharide-induced lung injury in rats. Shock 34: 196-204, 2010.

11. Hur J, Yoon CH, Kim HS, Choi JH, Kang HJ, Hwang KK, Oh BH, Lee MM and Park YB: Characterization of two types of endothelial progenitor cells and their different contributions to neovasculogenesis. Arterioscler Thromb Vasc Biol 24: 288-293, 2004

12. Yoon CH, Hur J, Park KW, Kim JH, Lee CS, Oh IY, Kim TY, Cho HJ, Kang HJ, Chae IH, et al: Synergistic neovascularization by mixed transplantation of early endothelial progenitor cells and late outgrowth endothelial cells: The role of angiogenic cytokines and matrix metalloproteinases. Circulation 112: 1618-1627, 2005.

13. Yu M, Zhang Q, Liu Q, Sun J, Yang G, Zeng G and Tan X: Lipopolysaccharide impaired the functional activity of endothelial colony-forming cells. Respiration 87: 317-323, 2014. 
14. Ye J, Liu Z, Wei J, Lu L, Huang Y, Luo L and Xie H: Protective effect of SIRT1 on toxicity of microglial-derived factors induced by LPS to PC12 cells via the p53-caspase-3-dependent apoptotic pathway. Neurosci Lett 553: 72-77, 2013.

15. Yu M, Liu Q, Yi K, Wu L and Tan X: Effects of osteopontin on functional activity of late endothelial progenitor cells. J Cell Biochem 112: 1730-1736, 2011.

16. Yu M, Liu Q, Sun J, Yi K, Wu L and Tan X: Nicotine improves the functional activity of late endothelial progenitor cells via nicotinic acetylcholine receptors. Biochem Cell Biol 89: 405-410, 2011.

17. Yu M, Li Z, Shu Z, Liu Q, Sun J and Tan X: Nicotine promotes late endothelial progenitor cells functional activity in a PI 3-kinase-dependent manner. Cell Biochem Biophys 70: 1023-1028, 2014.

18. Hennessy EJ, Parker AE, O'Neill LA: Targeting Toll-like receptors: Emerging therapeutics? Nat Rev Drug Discov 9: 293-307, 2010.

19. Ha T, Liu L, Kelley J, Kao R, Williams D and Li C: Toll-like receptors: New players in myocardial ischemia/reperfusion injury. Antioxid Redox Signal 15: 1875-1893, 2011.

20. Medzhitov R, Preston-Hurlburt P and Janeway CA Jr: A human homologue of the Drosophila Toll protein signals activation of adaptive immunity. Nature 388: 394-397, 1997.

21. Triantafilou $K$, Triantafilou $M$ and Dedrick RL: $A$ CD14-independent LPS receptor cluster. Nat Immunol 2: 338-345, 2001.

22. Inohara N, Ogura Y, Chen FF, Muto A and Nuñez G: Human Nod1 confers responsiveness to bacterial lipopolysaccharides. J Biol Chem 276: 2551-2554, 2001.

23. Qin L, Li G, Qian X, Liu Y, Wu X, Liu B, Hong JS and Block ML: Interactive role of the toll-like receptor 4 and reactive oxygen species in LPS-induced microglia activation. Glia 52: 78-84, 2005

24. Zheng W, Zheng X, Liu S, Ouyang H, Levitt RC, Candiotti KA and Hao S: TNF $\alpha$ and IL-1 $\beta$ are mediated by both TLR4 and Nod1 pathways in the cultured HAPI cells stimulated by LPS. Biochem Biophys Res Commun 420: 762-767, 2012.

25. McGhan LJ and Jaroszewski DE: The role of toll-like receptor-4 in the development of multi-organ failure following traumatic haemorrhagic shock and resuscitation. Injury 43: 129-136, 2012.

26. Purushotham A, Schug TT, Xu Q, Surapureddi S, Guo X and Li X: Hepatocyte-specific deletion of SIRT1 alters fatty acid metabolism and results in hepatic steatosis and inflammation. Cell Metab 9: 327-338, 2009.

27. Bordone L, Motta MC, Picard F, Robinson A, Jhala US, Apfeld J, McDonagh T, Lemieux M, McBurney M, Szilvasi A, et al: Sirt1 regulates insulin secretion by repressing $\mathrm{UCP} 2$ in pancreatic beta cells. PLoS Biol 4: e31, 2006.
28. Yang Y, Duan W, Li Y, Jin Z, Yan J, Yu S and Yi D: Novel role of silent information regulator 1 in myocardial ischemia. Circulation 128: 2232-2240, 2013.

29. Takeda-Watanabe A, Kitada M, Kanasaki K and Koya D: SIRT1 inactivation induces inflammation through the dysregulation of autophagy in human THP-1 cells. Biochem Biophys Res Commun 427: 191-196, 2012

30. Wang X, BuechlerNL, Yoza BK, McCallCEand Vachharajani VT: Resveratrol attenuates microvascular inflammation in sepsis via SIRT-1-Induced modulation of adhesion molecules in ob/ob mice. Obesity (Silver Spring) 23: 1209-1217, 2015.

31. Yang L, Zhang J, Yan C, Zhou J, Lin R, Lin Q, Wang W, Zhang K, Yang $\mathrm{G}$, Bian X and Zeng A: SIRT1 regulates CD40 expression induced by TNF- $\alpha$ via NF- $\kappa$ B pathway in endothelial cells. Cell Physiol Biochem 30: 1287-1298, 2012.

32. Moon MH, Jeong JK, Lee YJ, Seol JW, Jackson CJ and Park SY: SIRT1, a class III histone deacetylase, regulates TNF- $\alpha$-induced inflammation in human chondrocytes. Osteoarthritis Cartilage 21: 470-480, 2013.

33. Zarzuelo MJ, López-Sepúlveda R, Sánchez M, Romero M, Gómez-Guzmán M, Ungvary Z, Pérez-Vizcaíno F, Jiménez R and Duarte J: SIRT1 inhibits NADPH oxidase activation and protects endothelial function in the rat aorta: implications for vascular aging. Biochem Pharmacol 85: 1288-1296, 2013.

34. Ungvari Z, Orosz Z, Rivera A, Labinskyy N, Xiangmin Z, Olson S, Podlutsky A and Csiszar A: Resveratrol increases vascular oxidative stress resistance. Am J Physiol Heart Circ Physiol 292: H2417-H2424, 2007.

35. Spanier G, Xu H, Xia N, Tobias S, Deng S, Wojnowski L, Forstermann $\mathrm{U}$ and $\mathrm{Li} \mathrm{H}$ : Resveratrol reduces endothelial oxidative stress by modulating the gene expression of superoxide dismutase 1 (SOD1), glutathione peroxidase 1 (GPX1) and NADPH oxidase subunit (Nox4). J Physiol Pharmacol 60 (Suppl 4): S111-S116, 2009.

36. Li YG, Zhu W, Tao JP, Xin P, Liu MY, Li JB and Wei M: Resveratrol protects cardiomyocytes from oxidative stress through SIRT1 and mitochondrial biogenesis signaling pathways. Biochem Biophys Res Commun 438: 270-276, 2013.

37. Okuyama H, Tominaga A, Fukuoka S, Taguchi T, Kusumoto Y and Ono S: Spirulina lipopolysaccharides inhibit tumor growth in a Toll-like receptor 4-dependent manner by altering the cytokine milieu from interleukin-17/interleukin-23 to interferon- $\gamma$. Oncol Rep 37: 684-694, 2017. 